\title{
Principles of Elective Design with Industry-Institute Collaboration
}

\author{
Prakash Hegade ${ }^{1}$, Nirmala Patil ${ }^{2}$, Indira Bidari ${ }^{3}$ \\ ${ }^{12}{ }^{3}$ School of Computer Science and Engineering, KLE Technological University, Hubli-31 \\ ${ }^{1}$ prakash.hegade@kletech.ac.in \\ 2nirmalapatil@kletech.ac.in \\ 3indira_bidari@kletech.ac.in
}

\begin{abstract}
Along with core courses, an education program is usually designed with discretionary elective courses for professional advancement. It is naturally inherent that most electives' course contents need periodic apprise to persevere to the state-of-art. The pace at which industries adapt to new technologies is considerably rapid as compared to the teaching and learning that happens at the university. However, an elective design needs an equal role and support to be played by the industry and the institute. This paper proposes the design principles for an elective course, which envelopes from curriculum structure to evaluation methodologies. The principles are outlined to cover the design aspects, selection methodologies for the content and course materials, syllabus division to units, course learning outcomes, teaching pedagogy, industry principles, evaluation methodologies, and course learning attainment. Each principle is presented with an objective and deliberation. The intended principles were applied to the design and delivery of an elective - Semantic Web. The course, which was offered with an industry-institute collaboration, was opted by 125 students in the sixth semester. The paper further presents each of the principles as applied and delivered for the semantic web course. The course attainment with respect to course learning outcomes, student elective opt ratio, and the feedback obtained stand in favor of the proposed model. The principles can be applied to design the elective for enhanced learning experiences and make students industry-ready, which is one of the major objectives for introducing the electives.
\end{abstract}

Keywords: design, elective, industry, learning outcomes, principles

\section{Prakash Hegade}

School of Computer Science and Engineering, KLE

Technological University, Hubli.

prakash.hegade@kletech.ac.in

\section{Introduction}

A degree program curriculum customarily has a theory, practical, and project mode of delivery attained through a variety of practices. Contemporary advancements in teaching and learning pedagogy have also introduced variants like tutorials, studio mode classes, project-based learning, etc. Each of the newly introduced segment targets to achieve a blooms level of application, analysis, and beyond. In regards, programs have designed elective courses to instill and enhance skillsets for professional growth. Electives also contribute to personal development (Altunbay, 2018).

Electives are usually offered for various reasons. Along with professional development, it also contributes to numerous other factors. Electives help in understanding a course depth-wise and also go with the breadth horizon to understand interdisciplinary acquaintances. While some electives help one to specialize in a domain of interest, others might help to explore a new area of study. They instill confidence in students by growing their interest in a specific domain. Electives help students to gain a profound perspective contributing to the growth of professional welfares and abilities.

Once students complete all the core courses mandated by the program, they are presented with a set of electives they could opt for. Every university has its own set of objectives for an elective design and offer. From operational, cocurricular strength to performance, they are targeted to discrete fragments. Students are empowered and feel ownership when they opt for a particular course. Electives bring out the state-of-art, open up a fun world, and help students grow.

Having known the importance of electives, universities have a greater responsibility for designing and delivering them effectively. While the core course syllabus remains the same for a few years, electives usually see frequent changes and updates. Especially in the field of engineering, with continuous apprises, elective syllabus demand a recurrent change.

The design of an elective has its own challenges. While the institutes focus majorly on the theory and their principles, industries need the applications and practical know-how. With swift advancements in technology, students need to be elucidated with underlying pedigrees and life cycles where they can adapt the learnings to any forthcoming technological developments. This can be achieved and lead to its success only when an elective is designed in collaboration with institutes and industries. The right principles need to be laid out for the operative realization of the courses.

This paper proposes a design principle model for elective design and delivery. Section 2 presents the literature survey. Section 3 presents the principle model. Section 4 presents a 
case study of applying the model to a course Semantic Web and also presents the results and discussion. Section 5 presents the conclusion.

\section{Literature Survey}

Elective courses are targeted to enhance curricular and cocurricular capabilities directly or indirectly, leading to professional and personal developments (Jie, 2005). Elective courses to enhance retention beyond university have been comprehended, seeking towards learning and academic success (Higbee et. al., 2002). Ample research and study have been carried out on elective considerations; however, several open challenges still need addressing.

Electives have been analyzed with respect to relationships among social-contextual factors, individual differences, and intrinsic motivation. The relationship model has also been validated on different data samples (Ferrer-Caja and Weiss, 2000). The impact of course evaluation has been studied with respect to the training method employed, the trainer, and the student background (Darby, 2006). The choice of electives and their implications have been studied (Ding and Christina, 2012).

On the other end, even students are equally confused about the choice of elective courses. Recommendation systems have been designed to suggest electives to students (Bhumichitr et. al., 2017). Collaborative recommendation systems have been built to recommend the right courses to the students (Ray and Sharma, 2011). Models have also been developed to recommend courses using a hybrid multi-criteria with genetic optimization methods (Esteban et. al., 2020). Fuzzy logic systems have been designed to recommend electives (Adak et. al., 2016). The schedule of electives has been experimented using association rules via optimization algorithms (Susan and Bhutani, 2018). The factors that students consider to register for an elective have been studied as well (Amin et. al., 2009).

Not only the design and delivery, but there are also several other factors that play a role in the course effectiveness evaluation. For elective courses and course selections, reallife curriculum-based timetabling has been investigated (Müller and Rudová, 2016). Student opinions of elective courses in the changing education have been analyzed (Ulusoy et. al, 2012). Leadership elective courses have been offered where the senior students teach the juniors (Patterson, 2013). Interdisciplinary elective courses have been offered to enhance cross-domain knowledge and applications (Versypt, 2019).

Industry institute partnerships for engineering education have been studied and dates back to decades earlier (Tener, 1996). Educational strategies for industrial design have been studied with respect to the graduation project course (Evyapan et. al., 2005). Strategies have been devised to infuse global perspectives and industrial collaboration in engineering education (Jackson et. al., 2010). Industry institute collaborative domain-specific theme-based projects have been offered and evaluated (Patil et. al., 2020). Though there are industry collaborations in many aspects, there is no time-honored model for elective design yet.

With all the mentioned experiments and challenges at hand, the area calls for the right principles to achieve the sought after. Proper planning, feedback, and delivery is the need of the hour.

\section{The Principle Design Model}

This section details out our proposed model with the design goals, the foundational components of the course design, and the principles derived from the components.

\section{A. Design Goals}

The purpose of designing this model is threefold and are listed below:

- To realize the importance of industry collaboration for an elective design

- To design state-of-art electives

- To provide the guiding principles for an elective design

B. Foundational Components

In order to derive the design principles, it is essential to identify the components that are an intricate part of the system and course design. The components identified can be seen in figure 1 below.

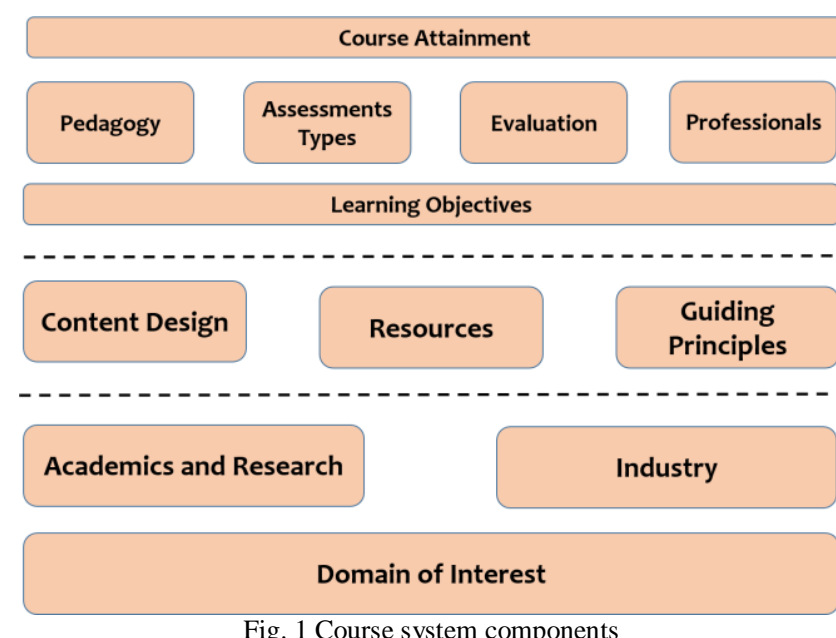

The components can be divided into three layers. In layer 1 is the academic and industry contribution to the domain of interest. In layer 2 are curriculum design, the resources available for curriculum design, and the guiding principles for the design. Layer 3 covers the learning objectives for the course attainment. Layer 3 has an additional component called 'Professionals'. Professionals component is a nonevaluation component that gives the holistic perspective of the course with respect to specialized skills.

\section{Elective Design Principles}


Following are the laid out principles for the elective design, which were crafted and concluded after six meetings of three hours each. The panel included members from academics and industry. Several course case studies were considered in crafting the principles. The key components can be seen below in figure 2 .

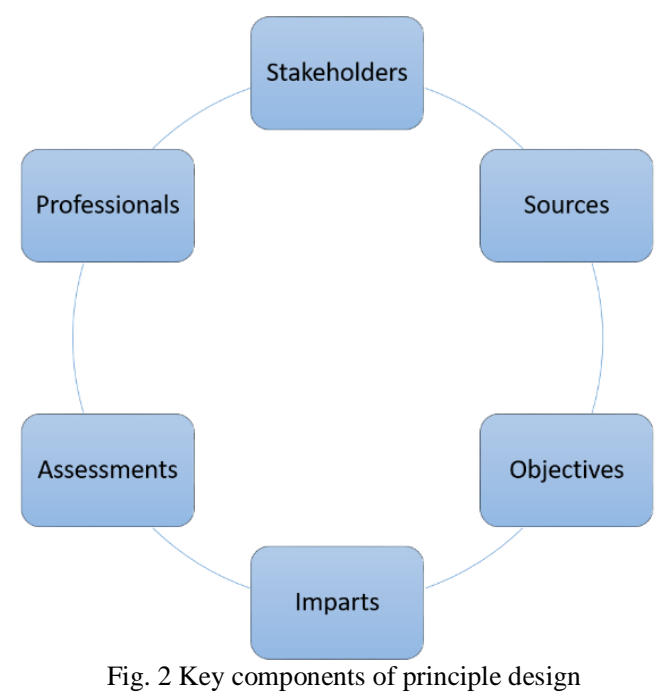

1) Principle One - all stakeholders are equal: If there are three stakeholders contributing to the syllabus design, then all of them play an equal role. If not equal, then they are not the stakeholders. A syllabus has to be a proper balance of each individual component. Each stakeholder has a specific role-play, typically coming either from industry or academics. Examples include theoretician, researcher, application developer, associate engineer, etc.

2) Principle Two - sources are beyond the books: Textbooks are not the only means of reference. There are industry case studies, research papers, applications, and many others that can be looked for. There are always more resources than we actually see and know of. The compartmentalization of the syllabus also plays a major role. A syllabus designed must never be cent percent theory, nor cent percent applications.

3) Principle Three - objectives are atomic: course learning objectives must be written by keeping in mind the pedagogy, assessment, and attainment. They must not be sentences that drift with dangling and weasel words. Every objective must aim to reach a learning taxonomy.

4) Principle Four - impart abstractions: a course should not only explain a concept but explain the guiding principles for the future scope. Delivery methods and modes have to be appropriately decided based on the course content and relevance.

5) Principle Five - assessments for inclusive learning: written exams and quizzes are not the only ways of assessment. Every elective must adapt to the effective measure of evaluation than the one employed for the traditional courses. An elective might require an on-filed evaluation and another a project-based learning. Also, it is not necessary that every component of the course needs to be assessed and considered for the evaluation.

6) Principle Six - the professional paradigm: an elective must connect and comprehend professional growth. After completion of the course, the student must carry the required course attitude and culture.

\section{Semantic Web - Case Study}

The School of Computer Science and Engineering of KLE Technological University has introduced elective subjects in the Engineering curriculum from the sixth semester onwards. These elective subjects are categorized into domains as web-based engineering, system engineering, data engineering, and network engineering. The electives in each domain are revised every academic year with the inputs given from the Board of Studies to keep the syllabus up-to-date with the industry standards and expectations. The students have the option of choosing their interested domain. This choice of the domain gives students the freedom to explore the area of interest. It does not restrict the learnability of students to a specific subject.

An elective 'Semantic Web' was designed in collaboration with KLE Technological University and Knit Arena Software Research and Services Private Limited. The elective was offered for sixth-semester students under the data engineering category for three credits. The course had 40 hours of the syllabus to be delivered. The elective was opted by 125 students and relatively graded. This section walks through from the course design to course attainment as per the discussed principles in section 3 .

\section{A. Objective}

The household discussion in the community is that the semantic web is dead. But in reality, the fact is that after machine learning and artificial intelligence took over, it gave a new perception to the web. The current conceptual understanding is obsolete, but the web certainly requires semantics. It needs to now tailor according to the platform set by learning and intelligence

The objective of designing this elective was to bring out the principles of the semantic web, discuss on what failed and then inspire to build models for the contemporaneous web demands. The course aimed to impart the principles required to build a better web for tomorrow. The stakeholders identified were semantic web researchers, instructors from web technology courses, and developers working on semantic web applications.

\section{B. Curriculum Design and Delivery}

The curriculum was designed jointly by the institute and industry. There were two in-person meetings and more online discussions carried out for the purpose. Resources like textbooks, research papers, case studies, start-ups on the domain, applications, etc., were considered. Even 
technologies that are obsolete and are considered a failure were made part of the syllabus. In consideration of the academic delivery structure, the course was divided into three units.

Unit I was designed to cover the semantic web principles, tools, and techniques. The unit aimed to provide the literature survey. Unit II was designed to cover the state-ofart needs and challenges deliberated by industry. The syllabus also included research papers and societal challenges. Unit III covered the applications and shed light on future models that are needed to realize a meaningful semantic web.

\section{Course Learning Outcomes}

The Course Learning Outcomes (CLO's) designed for the course are listed in Table 1.

Table 1. CLO's for the Course

\begin{tabular}{|l|l|}
\hline CLO id & \multicolumn{1}{|c|}{ CLO } \\
\hline CLO1 & $\begin{array}{l}\text { Examine and analyze data and its properties for } \\
\text { the semantic web }\end{array}$ \\
\hline CLO2 & $\begin{array}{l}\text { Explain the need to understand data, express } \\
\text { and use it for the semantic web }\end{array}$ \\
\hline CLO3 & $\begin{array}{l}\text { Investigate and explain the tools and models to } \\
\text { work with semantic data }\end{array}$ \\
\hline CLO4 & $\begin{array}{l}\text { Compare and analyze the semantic web } \\
\text { principles with state-of-art tools, techniques, } \\
\text { and principles }\end{array}$ \\
\hline CLO5 & Realize models for the semantic web. \\
\hline
\end{tabular}

Each of the above CLO's was mapped to program learning outcomes. For each CLO, in order to measure the attainment, a threshold and target were set. The threshold was set for each CLO depending on the complexity and level of assessment. The target indicates the percentage of students, and it is a common number set across all the CLO's. Table 2 presents the target and threshold for each CLO. As an example, the numbers can be interpreted as $75 \%$ of students must score $65 \%$ or more marks allotted for CLO5.

Table 2. CLO Threshold and Target

\begin{tabular}{|l|c|c|}
\hline CLO id & Threshold & Target \\
\hline CLO1 & $70 \%$ & $75 \%$ \\
\hline CLO2 & $60 \%$ & $75 \%$ \\
\hline CLO3 & $60 \%$ & $75 \%$ \\
\hline CLO4 & $65 \%$ & $75 \%$ \\
\hline CLO5 & $65 \%$ & $75 \%$ \\
\hline
\end{tabular}

The assessment was premeditated to be evaluated on the following basis: if the set target is achieved as per table 2, a number of 3 is scored. If it is $10 \%$ less than the set, a number of 2 is scored. If $55 \%$ of students score the set threshold, then a number 1 is scored. Anything lesser is scored to 0 .

\section{Delivery Modes}

The delivery of the syllabus employed several methods. Powerpoint presentations were used for limited concepts and as a mode to present and discuss the case studies. There were classes that were conducted in studio mode and involved brainstorming, discussion, and critique of the learned concepts.

Industry lectures were scheduled and delivered especially to cover unit II. Paper reading sessions were organized where students in groups read papers, summarized, and critiqued. Students in teams browsed over web applications and prepared a report building new models to adhere to the semantic web principles. There were also sessions conducted discussing social semantics and their effect on technology design. The course takeaway session addressed how the current architecture can be changed to meet contemporary needs (this was designed to attain the professionals principle).

\section{E. Assessments}

Assessments were designed based on curriculum design and outcomes to be achieved. A total of 100 marks was split, as mentioned in Table 3 below. Mapping to CLOs is not mentioned in the table as each component had mapping to more than one CLO with respective rubrics.

Table 3. Assessment Parameters and Marks

\begin{tabular}{|c|l|c|}
\hline Sl. No. & \multicolumn{1}{|c|}{ Assessment Type } & Marks \\
\hline 1 & Minor Exam 1 & 30 \\
\hline 2 & Open Book Exam & 15 \\
\hline 3 & Coursera Course & 05 \\
\hline 4 & Portfolio Assignment & 20 \\
\hline 5 & End Semester Exam & 30 \\
\hline \multicolumn{2}{r|}{ Total } & 100 \\
\hline
\end{tabular}

Minor exam 1 was a written exam that covered the Unit I syllabus. As the syllabus covered literature and theory principles, a written exam was conducted. An open book exam was conducted for Unit II as the syllabus had industry contents and delivery. The open book exam was divided into two sessions on the same day. Students had an option to answer one question out of two in both sessions, and each session was of 2.5 hours. Students were asked to complete the course from Coursera 'Web of Data' offered by EIT Digital to get a global perspective on the subject matter. The course had a portfolio assignment which was carried out in teams of 3-4 by taking a real-world problem and addressing the semantic issues of the domain for the modern web. The course also had an end semester examination to provide a holistic theory and application evaluation. However, the end semester exam concentrated on Unit II and Unit III only.

F. Attainment

The overall attainment of all CLO's for the course can be seen in Table 4. The calculation details are as briefed in section $4 \mathrm{C}$. 
Table 4. Course CLO Attainment

\begin{tabular}{|l|c|}
\hline CLO id & Attainment Score \\
\hline CLO1 & 3.00 \\
\hline CLO2 & 2.36 \\
\hline CLO3 & 2.11 \\
\hline CLO4 & 2.29 \\
\hline CLO5 & 1.87 \\
\hline
\end{tabular}

CLO5 had the least attainment, which was because of the portfolio assignment. As students did the portfolio assessment for the first time, they expressed the need for more clarity in the process. This was a learning for students and the faculty team. The overall course results were satisfactory.

The overall grading of the class can be seen below in Figure 3. Majority of the class was in the range of $\mathrm{S}$ to $\mathrm{B}$ grades.

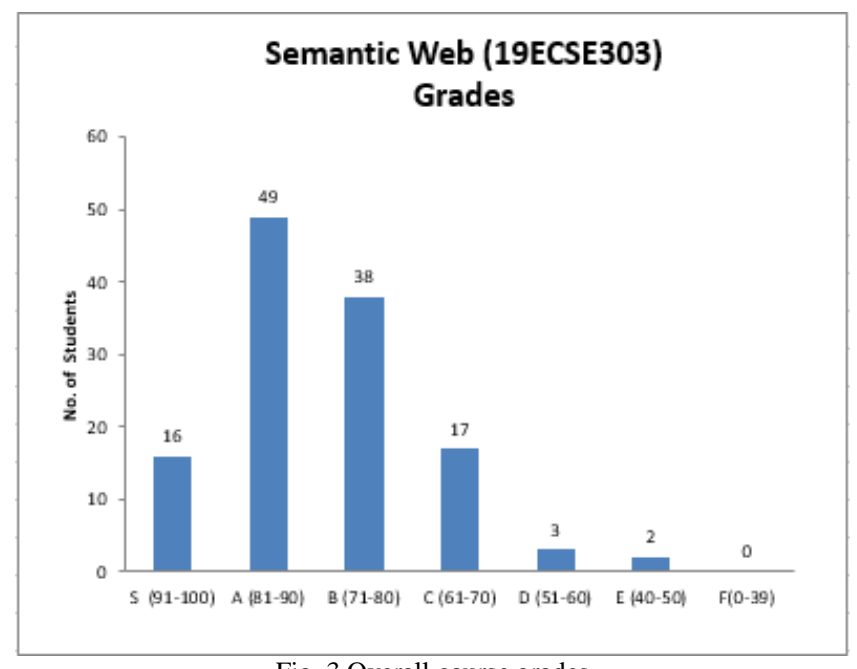

Fig. 3 Overall course grades

\section{G. Closure}

A feedback sheet was circulated to students to measure the course effectiveness, and this section presents the results of the feedback. The form data was submitted by 82 students. Students had to rate each question with one of the below mentioned options:

- $\quad$ highly ineffective (1)

- $\quad$ ineffective (2)

- $\quad$ neutral (3)

- effective (4) and

- $\quad$ highly effective (5)

The questions and their respective graphs are presented in the order ahead.

Question 1: How relevant/effective did you find the course syllabus?

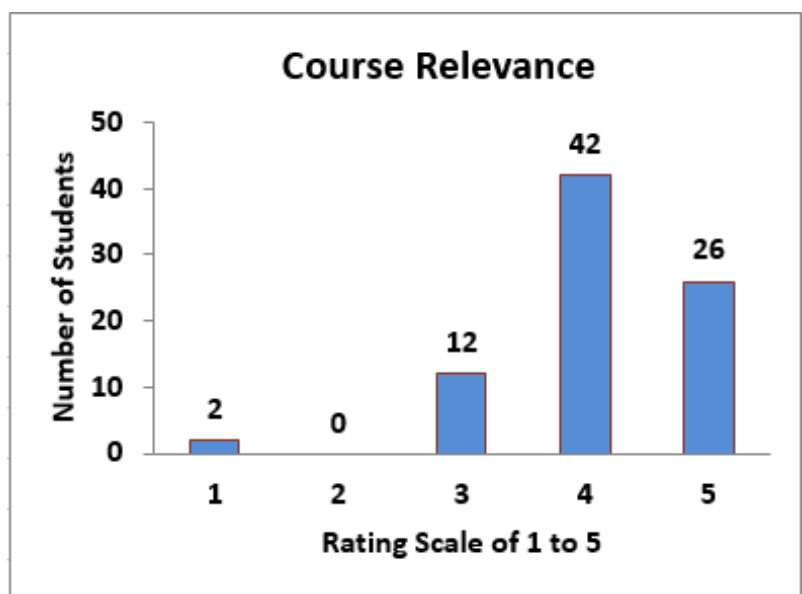

Fig. 4 Feedback on course relevance

Question 2: How effective was the portfolio assignment?

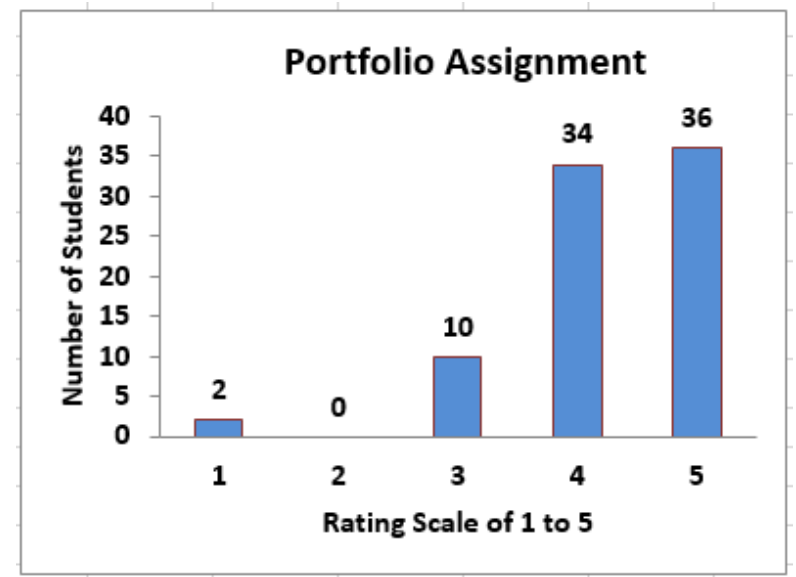

Fig. 5 Feedback on portfolio assignment

Question 3: Your opinion on open book exam

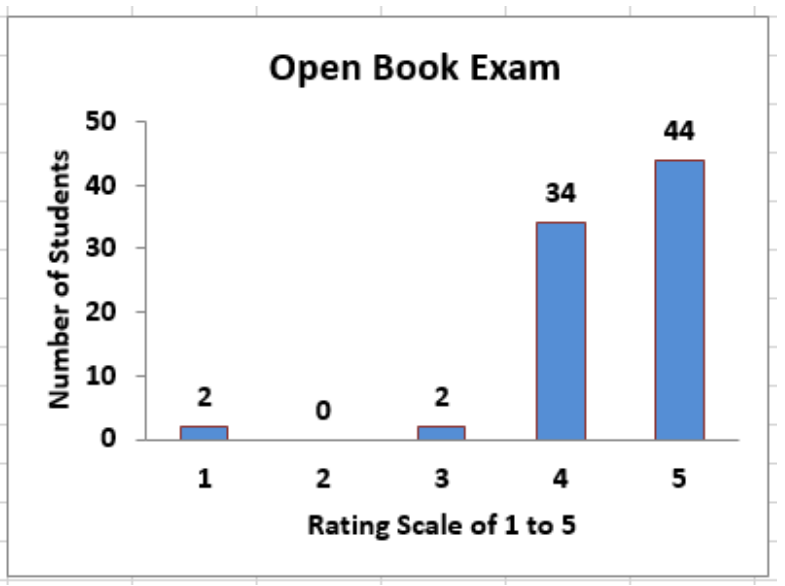

Fig. 6 Feedback on open book exam

Question 4: The syllabus was not completely based on textbooks but also incorporated industry case studies and published papers. Your opinion. 


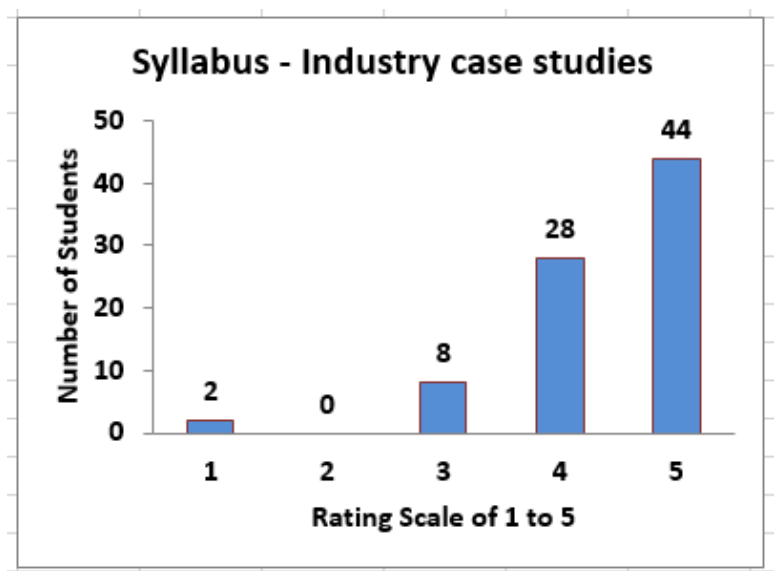

Fig. 7 Feedback on resources

Question 5: Overall course feedback

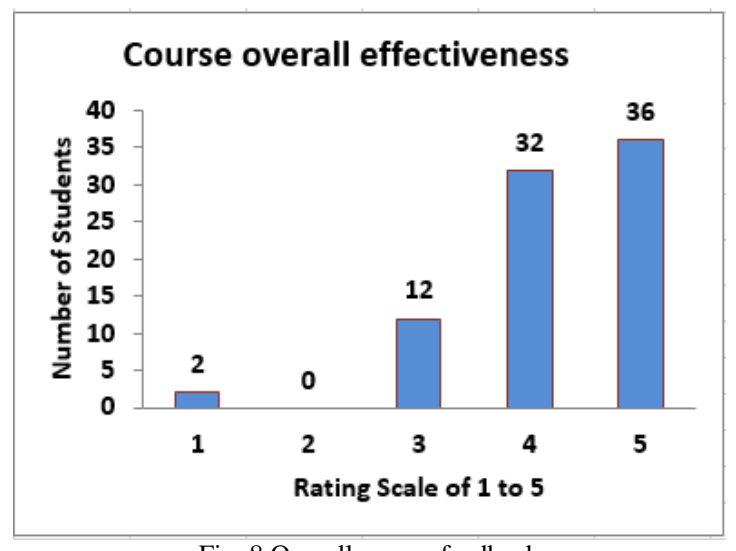

Fig. 8 Overall course feedback

Question 6: Would you recommend this course to your juniors? (Where 1 was definitely no and 5 was definitely yes)

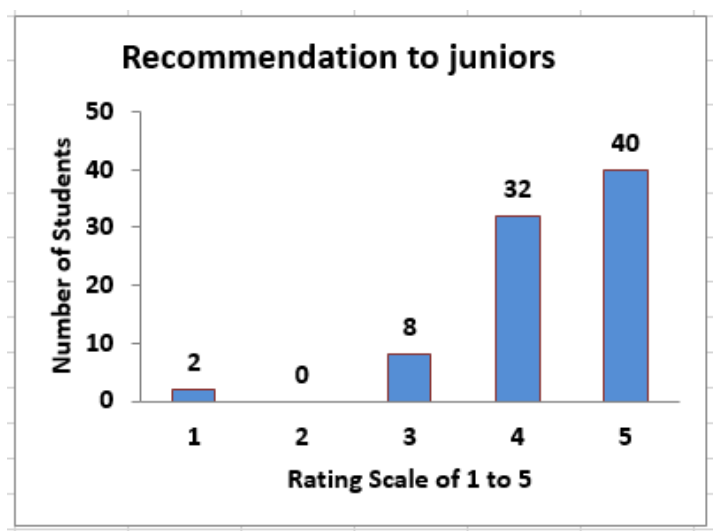

Fig. 9 Course recommendation to juniors

The feedback statistics are self-explanatory, and course delivery was satisfactory with respect to the course attainment and the feedback. Additional text feedback was also collected, where many students requested more industry interaction and case studies. Another significant fact was that the course had the highest registrations as compared to other electives offered during the semester. The feedback obtained for question 6 is an assurance for the trend to continue in the future.

\section{Conclusion}

Electives play a major role in professional growth and development. This paper presented a principle model for the design and delivery of an elective. The six principles guide through for elective courses design from curriculum to attainment. Elective courses need stakeholders support, and industry collaboration is an essential aid. Be it a small scale or large scale, start-up, or a well-established, an elective designed with conglomerate can promise a better delivery. The partnership not only means in syllabus design but also extends for delivery and assessments. The model proposed promises to be an effective strategy to meet the state-of-art challenges and evolving solicitations.

The principles need validation from different courses and a structured format to guide through and be applicable to other domains. The future scope of this work would involve building a template for each principle with an extendable work log.

\section{Acknowledgement}

The authors wish to thank Knit Arena for their contribution in design and delivery of the elective. They would also like to thank the timely support in every regards for the collaboration in principles design to planned delivery.

\section{References}

Altunbay, M. (2018), The Effects of Elective Courses on the Personal Development of Prospective Teachers. Universal Journal of Educational Research. 6. 2094-2100. 10.13189/ujer.2018.061006.

Adak MF, Yumusak N and Taskin H. (2016), An elective course suggestion system developed in computer engineering department using fuzzy logic. In2016 International Conference on Industrial Informatics and Computer Systems (CIICS) 6 Mar 13, pp. 1-5, IEEE.

Amin, H., Rahman, A.R.A. and Ramayah, T. (2009), What makes undergraduate students enroll into an elective course?. International Journal of Islamic and Middle Eastern Finance and Management. 2. 289-304.

Bhumichitr, K., Channarukul, S., Saejiem, N., Jiamthapthaksin, R. and Nongpong, K. (2017), Recommender Systems for university elective course recommendation. In 2017 14th International Joint Conference on Computer Science and Software Engineering (JCSSE), pp. 1-5, IEEE.

Darby, J.A. (2006), The effects of the elective or required status of courses on student evaluations. Journal of Vocational Education and Training, 58(1), pp.19-29. 
Ding, H. T. and Christina, K. C. L. (2012), Understanding students' choice of electives and its implications, Studies in Higher Education, 37:3, 309-325, DOI: 10.1080/ 03075079.2010.512383.

Esteban, A., Zafra, A. and Romero, C. (2020), Helping university students to choose elective courses by using a hybrid multi-criteria recommendation system with genetic optimization. Knowledge-Based Systems, 194, p.105385.

Evyapan, N., Korkut, F. and Hasdoğan, G. (2005), Implications of collaboration with industry for educational strategies in industrial design: the graduation project course. METU, Faculty of Architecture Press, Ankara, pp.137-159.

Ferrer-Caja, E. and Weiss, M.R. (2002), Cross-validation of a model of intrinsic motivation with students enrolled in high school elective courses, The Journal of Experimental Education, 71(1), pp.41-65.

Higbee, J.L., Dwinell, P.L. and Thomas, P.V. (2002), Beyond University 101: Elective courses to enhance retention. Journal of College Student Retention: Research, Theory \& Practice, 3(4), pp.311-318.

Jackson, H., Tarhini, K., Zapalska, A. and Zelmanowitz, S. (2010), Strategies to infuse global perspectives and industrial collaboration in engineering education. In 2010 IEEE Frontiers in Education Conference (FIE) pp. S1J-1, IEEE.

Jie, Q.I.N. (2005), research on the Development of the Elective Courses in Higher Education [J], Journal of Beijing University of Physical Education, 6.

Müller, T. and Rudová, H. (2016), Real-life curriculumbased timetabling with elective courses and course sections. Annals of Operations Research, 239(1), pp.153170.

Patil, U., Iyer, N., Budihal, S., Ramesh, T., Heera, W. and Rohit, K. (2020), Industry Institute Collaborative Domain specific Theme Based Projects. Procedia Computer Science, 172, pp.181-186.

Patterson, B.J., Garza, O.W., Witry, M.J., Chang, E.H., Letendre, D.E. and Trewet, C.B. (2013), A leadership elective course developed and taught by graduate students. American journal of pharmaceutical education, 77(10).

Ray, S. and Sharma, A. (2011), A collaborative filtering based approach for recommending elective courses. In International Conference on Information Intelligence, Systems, Technology and Management, pp. 330-339, Springer, Berlin, Heidelberg.
Susan, S. and Bhutani, A. (2018), Data Mining with Association Rules for Scheduling Open Elective Courses Using Optimization Algorithms. In International Conference on Intelligent Systems Design and Applications, pp. 770-778, Springer, Cham.

Tener, R.K. (1996), Industry-university partnerships for construction engineering education. Journal of Professional Issues in Engineering Education and Practice, 122(4), pp.156-162.

Ulusoy, Y.Ö., Dağ, F., Fidan, D., Sahranç, Ü., Inan, B. and Güllü, D. (2012), Students opinions about elective courses in changing education: The example of Kocaeli University Faculty of Education. Journal of Educational and Instructional Studies in the World, 2(4), pp.135-142.

Versypt, A.N.F. (2019), November. Building Computational Skills for Mathematical Modeling in Science and Engineering through an Interdisciplinary Elective Course. In 2019 AIChE Annual Meeting. AIChE. 